\title{
Country Report
}

\section{Fiji}

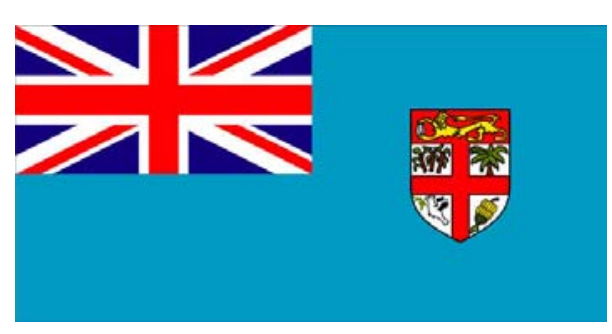

\section{REORIENTING TVET POLICY TOWARDS EDUCATION FOR SUSTAINABLE DEVELOPMENT}

\author{
ALUMECI SUSU TUISAWAU \\ SENIOR EDUCATION OFFICER TVET \\ MINISTRY OF EDUCATION, FIJI ISLANDS \\ TEL. NO.: (+679) 331447 EXT 540 OR 3200027 \\ FAX NO:: (+679) 331373 \\ MOBILE NO.: (+679) 7367077 \\ Email: alumeci.tuisawau@govnet.gov.fj
}

$17^{\text {th }}$ August, 2009 


\begin{abstract}
TVET plays an equally important role in the social, economic and political development of any nation together with its academic counterpart. However, Fiji has not fully realized its potential and has treated it as a 'second best option' to academic education. TVET is gradually gaining the attention it deserves in the total learning system of all Fiji citizens. Education is regarded as the key to development, however, TVET is seen as 'the master key' because it has the ability to open all the 'doors' of life-long learning and improve the vocational expertise and consequently the quality of living. It is envisaged that stakeholders would be empowered especially the policy-makers, so that they can genuinely accept TVET as an equally important component of the total learning system providing relevant knowledge, skills and competencies for employability, improvement of quality living and learning communities. TVET needs to focus on the three dimensions of sustainability which are economic, social and environment. The current TVET curriculum has little emphasis on sustainable development and the model which is currently being used in Fiji is the infusion model.
\end{abstract}

\title{
1.0 Rationale
}

Education is an essential tool for achieving sustainability. Fiji continues to pursue developments in Education that will provide the basis for future directions and security through an educated and civil people who have pride for their country and identity, a deep respect for their heritage and the ability to grow and live in a global environment. The changes to knowledge required means that the education system must be ready to respond to needs that will place its products favourable in respect of the demands for life skills and the workplace. (Filipe Bole, Minister of Education, 2009)

The importance of Human Resources to the achievements of the Ministry's vision and mission cannot be overemphasized. Being a labour intensive industry, education requires the appointment and retention of a skilled workforce as well as the continual upgrading of their qualifications. A well qualified teaching force is essential for the strive towards quality education and excellence in service delivery.

The right to development implies the right to improvement and advancement of economic, social, cultural and political conditions. Improvement of global quality of life means the implementation of change that ensures every person a life of dignity; or life in a society that respects and helps realize all human rights. These changes must include the eradication and alleviation of widespread conditions of poverty, unemployment, and inequitable social conditions. Sustainable development ensures the well-being of the human 
person by integrating social development, economic development, and environmental conservation and protection.

Technical Vocational Education \& Training (TVET) in Fiji has been around in our secondary school system for over five decades. Although it has been globally recognised by UNESCO as an important component of education, it has never been provided with appropriate financial support to raise its current standard to the level that it deserves. TVET has maintained a steady progress in the provision for a balanced curriculum ensuring, to some degree a holistic approach to the predominantly academic curriculum.

Technical Vocational Education and Training (TVET) have suffered from being considered as the fall-back option for those who do not succeed in the more 'academic streams'. It was only during the recent decades that this perception has been globally and nationally challenged and altered. A major reason for this modification has been the changing role of work and its impact on national and international economies and with work becoming more technologically based and more diverse, thus reducing the opportunities for unskilled work, TVET has assumed a key educational role.

\subsection{Present Status on TVET Programs in relation to Education for Sustainable Development (ESD)}

\section{Background of TVET in the School Sector}

TVET is an important aspect of the total learning package of the child as well as the adult learner. This view is consistent with Delors' Report (UNSCO, 1996) that perceives education as providing the all-round development of a child's personality. It identifies a range of learning opportunities that students need to experience in order to be adequately prepared for active participation in all aspects of living. To achieve this, the Delors' Report suggests that the overall education of the learner should be rebuilt around four pillars: 'learning to know', 'learning to do', 'learning to live together' and 'learning to be'. In this regard, TVET in the school sector has a crucial as well as a complementary role to play in preparing an educated citizenry who is more likely to champion "the ideals of peace, freedom, and social justice" (UNESCO, 1996, p.13).

Similarly, the United Nations Decade of Education for Sustainable Development, launched in 2005, the Millennium Development Goals and the Education for All movement express similar sentiments about TVET giving it the status of the 'master key' to social, economic and political development. Quisumbing (in Prospects, Vol. XXXV, No3, September 2005: 300) emphasizes: 


\begin{abstract}
Quality TVET needs a teaching/learning approach that does not stop at knowledge and information nor at developing skills and competence, but proceeds to understanding and gaining insights that educates the heart and the emotions and develops the ability to choose freely and to value, to make decisions and to translate knowledge and values into action. Values education is a necessary component of the holistic work education and citizenship education.
\end{abstract}

Therefore, there is urgency to reconceptualise TVET making it an essential part of the education curriculum not only of the Pacific island nations (PINs) but also globally.

It is underscored, however, that TVET has suffered from being considered as the fall-back position for those for those who did not succeed in academic education streams. This viewpoint has changed considerably now. A major reason for this shift in thinking is the changing character of work and its impact on social and economic development. All sectors of employment are now becoming so technologically-based, diverse and dynamically complex that most unskilled workers find it difficult to obtain gainful employment. Therefore, TVET is now seen as playing a complementary role in 'skilling' primary and secondary school students and 'up-skilling' industry and other workplace employees. TVET can provide both the link with productive work and motivation for life-long education and training. It has the capacity to incorporate pacific knowledge, technologies and life-skills as well as indigenous pedagogy in the learning agendas. In Fiji, for example, TVET was given impetus when the Fiji Islands Education Commission (1969, p.14) found that the school curriculum lacked "relevance in many of its subject areas to the local environment and to local needs". Despite numerous curriculum reforms promoting vocational education and training in Fiji as well as other PINs have not yet succeeded sufficiently in enriching their school curricula with vocational education and the above-mentioned Pacific flavour.

In brief, then, it suffices to mention here that TVET has the potential to contribute to sustainable development, education for all, knowledge society and citizenship. Phillip Hughes explains (in Prospects, vol. XXXV, no3, September 2005: 263):

TVET now involves such a variety of approaches, including both formal and informal education, that it can supplement the formal systems of schools in ways that will increase their effectiveness. TVET addresses needs that are fundamental to human motivation and achievement, in particular the capacity of work productively and creatively.

TVET initiatives in most developing countries stemmed from the realisation that not all children respond favourably to the formal and academic type of education. It is the minority of the secondary school-leavers who find either employment or places in tertiary institutions while the majority struggle to find opportunities for 
work. The most commonly articulated goals of technical vocational education and training are listed below:

- to facilitate economic development by transmitting to local citizens certain values, knowledge and attitudes that are necessary to perform certain skills in the modern sector of the economy,

- to provide young people with the skills needed for employment in a wide range of job categories including self-employment and wage employment,

- to promote a work ethic and sensitise learners to the importance of practical work skills and the dignity of manual labour,

- to promote sustainable development, save the environment and improve the quality of living,

- to alleviate unemployment as well as poverty,

- to reduce the mass movements of school-leavers from rural to urban areas,

- to provide an alternative route to higher academic education for early secondary school-leavers,

Education systems in many developing countries are highly dependent on Western intellectual models, which are essentially academic in content and orientation. In recent decades, however, such systems have faced difficulties that are seen by many to represent a 'crisis' in formal education for developing countries. Major problems include access to educational opportunities, high school push-out rates and the worsening phenomenon of educated unemployment. The problem of a large number of school push-outs exists especially among poorer sections of the population. Educated unemployment and associated social problems have arisen because job opportunities fail to keep pace with the rising expectations of those with formal education qualifications. In this context, the concept of technical and vocational education remains attractive to many educational policy-makers. Consistent with this worldwide trend, Fiji has for some time attempted to incorporate significant technical and vocational initiatives within its educations system.

The Education Commission Report 1969 proposes the introduction of vocational education in secondary schools in Fiji to cater for the needs of school leavers providing education and training for paid employment that would lead students to higher education, to equip students for self employment and to provide life skills for those who would return to a rural life. This notion was further endorsed by Fiji Islands Education Commission Report 2000. The report stresses that 'dualism' in secondary schools will always be a threat to technical and vocational education. Over the years, technical and vocational education has struggled to get recognition from all sectors leaving a rather vague picture that skill-training is meant for those who are academically weak.

The present structure in the current TVET system saw it being offered and housed in more than one government ministries. The Ministry of Education, 
(MoE) manages the school-based TVET systems at primary, secondary and post-secondary school levels. Despite its semi-autonomous arrangement, FIT comes under MoE. The Monfort Boys' Town is classified as a private provider of TVET programs but currently receives an annual funding grant from MoE. The Advanced Vocational Training (AVT) program provides short-term training to the non-formal sector. It is managed by TVET section of MoE but is funded by the Ministry of Planning and National Development under its Integrated Human Resources Development Program (IHRD).

Private TVET vocational training institutions, such as the APTECH Computer School, are registered by MOE that recognises their qualifications and graduates. However, they are not closely monitored and do not receive financial or resource assistance from the Education Ministry. Other private TVET providers with agriculture-based training such as Tutu Vocational Centre are supported and funded by the Ministry of Agriculture.

The Fiji College of Agriculture is a fully government agricultural institution and provides a Diploma in Tropical Agriculture and this qualification is accredited by USP.

The Ministry of Forestry provides forestry skills training at its Forestry School in Colo-i-Suva and TITC in Nasinu. These organizations also provide short-term 'up skilling' courses for the workers of the forestry/timber industry.

The Technology sections of USP's School of Education, FIT Learning Centre and FCAE provide TVET teacher training programs at certificate, diploma and degree levels for those who wish to pursue 'TVET teaching' as a career.

\section{Currently TVET curriculum has been revised at the school level with emha}

\subsection{Best Practices on ESD in your country}

The three pillars of sustainable development are:

(i) Environmental sustainability

(ii) Economic sustainability

(iii) Social sustainability

Environmental Sustainability is embedded into all science and TVET curriculum in the new National Curriculum Framework which is outcome based. This needs to be strengthened in the content and the practical aspect of the TVET subjects. In the Agricultural Science curriculum the focus of sustainability is on Sustainable Agricultural Practices e.g. usage of natural resources wisely (largely due to the depletion of the natural resources due to rapid development); and minimizing wastes and limit damage to atmosphere to name a few. The minimization of the green house effects, the wise use of the raw materials, energy and water savings and the awareness of the impacts of production processes etc. are all part of the current curriculum. 
Economic sustainability expands the availability of work and the ability of individuals to secure an income to support themselves and their families. Economic development includes industry, sustainable agriculture, as well as integration and full participation in the global economy. Social and economic developments reinforce and are dependent on one another for full realization

The development of the Enterprise Education curriculum at primary and secondary level and the Vocational Business Studies ensures that students are taught the basic knowledge, skills, values and attitudes regarding economic literacy, sustainable production and management of small enterprises.

Social sustainability implies that the basic needs of the human being are met through the implementation and realization of human rights. Basic needs include access to education, health services, food, housing, employment, and the fair distribution of income. Social sustainability promotes democracy to bring about the participation of the public in determining policy, as well as creating an environment for accountable governance. Social sustainability works to empower the poor to expand their use of available resources in order meet their own needs, and change their own lives. Special attention is paid to ensure equitable treatment of women, children, people of indigenous cultures, people with disabilities, and all members of populations considered most vulnerable to the conditions of poverty.

The development and integration of citizenship education into the current curriculum ensures that social sustainability is taught across all levels and all disciplines. This will have to be included in the review of the TVET curriculum to be align to the NCF.

Fiji is striving towards compulsory and free education for all children. Compulsory education policy was introduced to ensure that all school age children have access to basic education.

A specific $\mathrm{NSDP}^{1}$ target states that net enrolment rates for secondary schools rise from $77 \%$ to $90 \%$ of the cohorts from form 1 by 2010 . Another states that the proportion of pupils who start class 1 and reach class 5 to be not less than $95 \%$.

The strategies that have been highlighted are the development of a curriculum that is grounded in local culture, values and lifelong skills, integration of students with special needs into regular schools, establishment of centres to pilot Distance Education and the expansion of Compulsory Education to all schools

${ }^{1}$ From the National Strategic Development Plan 2007-2011 
The modularization of the Competency Based Vocational curriculum ensures that short courses are developed which matches the labour market need. Enterprise education is another initiative by the Ministry of Education which targets specific skills and setting up small business enterprises in schools with the purpose of providing income to the schools and students. TVET subjects ${ }^{2}$ are now firmly embedded in the curriculum of Fiji. The sustainability of each subject is in question here with the negative growth in some (Appendix 1: Table 2-4). This shows the inclination of the students towards the academic subjects. In order to attract more students to TVET subjects currently the MoE is revising its TVET curriculum at all levels to become competency based, market driven, integration of sustainable development and aligned to the National Qualification Authority.

\subsection{Issues and Challenges in TVET on ESD in your country}

The issues and challenges of TVET with regards to ESD in Fiji are as follows:

- High youth unemployment $44 \%$ of world's unemployed are youth (ILO, 2006)

- Poverty reduction and economic growth: sustainable livelihoods

- Demands of globalization

- Image and status of TVET

- Access to TVET for all

- Training the trainers

- Importance of non-formal and informal approaches

- Lifelong learning

- Vocationalisation of secondary education

- Vocational content in higher education

- Public-private partnerships

4.1 The Challenge is for TVET to be regarded as the 'master key' of social, economic and political development because it has the potential to transform the world of work and the economy, alleviate poverty, save the environment, promote sustainable development and improve the quality of living.

4.1.1 To promote this philosophy, the relevant sections of the Government and the key stakeholders such as TVET providers need to develop appropriate education and empowerment programs for policy makers, schools, parents and other members of the school community. This

2 Sixteen TVET subjects are offered in secondary schools: agricultural science, computer education, office technology, home economics, clothing and textile, food and nutrition, apparel and design, food and technology, technical drawing, graphic arts, woodwork, food technology, engineering technology, metalwork, technical drawing and design and introduction to technology. 
readiness phase warrants full commitment as well as resource-support.

4.1.2 While maintaining control over all the phases of education and training process, the above mentioned advocates must establish the organizational climate and culture in which the TVET learning process can develop with the respect and vitality it deserves in the overall social, economic and political development. TVET must gradually become the norm of the school system.

4.2 The absence of an overall national TVET organizing authority for policy, planning, management, implementation, assessment and supervision.

4.3 The infusion of the ESD into the existing TVET curriculum

4.4 The successful implementation of TVET programs is constrained by the lack of readiness of stakeholders, lack of relevance of some of the programs and unavailability of suitable resources. The absence of relevant research-based data, especially on functional labour market, primary industry and TVET graduates, also hinders its successful planning and management.

4.5 The Education Ministry maintains very little contact with industries and informal sector as well as FIT, TPAF and other private providers of TVET. It develops its programs in isolation from the labour market. FIT and TPAF, however, have employer and employee representation on their Boards and through their industrial advisory committees receive feedback on the relevance of their programs. The workplace attachment of Education Ministry TVET program is poorly organized and the students do not receive useful on-the-job training.

4.6 TVET programs are not successfully implemented owing to the lack of appropriately qualified teachers and leaders. In particular, a large number of teachers have little industry experience in their teaching areas.

4.7 The quality of TVET training remains a problem in most rural areas and urban poor where training facilities are poorly equipped, under-financed and the expertise of teaching staff is inadequate.

4.8 The TVET curricula do not cater for job categories in which many young people with diverse social and economic backgrounds may find employment. There are major skill gaps 
4.9 Mismatch between knowledge and skills acquired and those available in the labour market. MoE must intitute 'research' studies to obtain correct information for future planning process.

4.10 The quality of courses and programs offered at FIT, TPAF and other TVET providers needs to be revisited so that they provide relevant knowledge, skills and competencies for employability and sustainability

4.11 The establishment of the National Qualifications Framework is necessary because it has the potential to establish standards and processes for quality control in FIT and TPAF as well as register and accredit other providers.

4.12 There is lack of an overall administrative and management structure for policy making, coordination, quality assurance and monitoring of TVET programs in Fiji with particular reference to, primary and secondary schools, FIT, TPAF and other TVET private providers.

\subsection{Conclusion}

There is a dire need to establish TVET policy and reorient it towards education for sustainable development. With the modularization of the Vocational curriculum, ESD should be included in the TVET training packages.

TVET could and should contribute to preparing better graduates from secondary schools and vocational centres by developing specific skills and increasing employability. There should be a clear articulation of the possible pathways for TVET in order to develop a whole person that has values, ethics, knowledge, attitudes and skills to contribute to a sustainable future. 


\subsection{Reference}

Sharma A. (2008) 'The Review of the Functions of FIT, TPAF and other TVET Providers'

Asian Development Bank. (2006) Skills Gap In the Pacific, Fiji Islands Case Studies (2006-2008), Prepared by: Paul Brady, Alex Gorham, Richard Johanson and Eci Naisele, Suva, FIJI

Education Sector Plan 2009-2011

\subsection{Appendix (s)}

\section{Structure of Formal TVET in Fiji}

\begin{tabular}{|c|c|c|c|c|}
\hline Level & Institution & Entry & Duration & Certification \\
\hline \multicolumn{5}{|c|}{ SECONDARY LEVEL } \\
\hline $\begin{array}{l}\text { Pre } \\
\text { vocational }\end{array}$ & 165 & & F3-4 & Compulsory \\
\hline $\begin{array}{l}\text { Pre } \\
\text { vocational }\end{array}$ & 165 & & F5-7 & Optional \\
\hline $\begin{array}{l}\text { Vocational } \\
\text { Centres }\end{array}$ & 62 & $\mathrm{~F} 4,5,6$ & 2 years & $\begin{array}{l}\text { MoE } \\
\text { Vocational } \\
\text { Certificate }\end{array}$ \\
\hline \multicolumn{5}{|c|}{ POST SECONDARY } \\
\hline Certificate & $\begin{array}{l}\text { FIT, FCA, } \\
\text { FSF }\end{array}$ & F6 & $\begin{array}{l}\text { 2yrs(5stages+work } \\
\text { exp) }\end{array}$ & $\begin{array}{l}\text { Trade } \\
\text { Certificate }\end{array}$ \\
\hline Diploma & $\begin{array}{l}\text { FIT, FCA, } \\
\text { FSF }\end{array}$ & F7 & 3years & \\
\hline Degree & FIT, USP & F7 & 3-4 years & \\
\hline
\end{tabular}

FIT=Fiji Institute of Technology; FCA-Fiji College of Agriculture; FSF-Fiji School of Forestry; USP-University of the South Pacific 